\title{
Effect of shot blasting on Aerial Aluminum Conductor corrosion behavior
}

\author{
Kai Guo ${ }^{1, a}$, Xiaoming Wang ${ }^{1, b}$, Zhiling Yu ${ }^{2, c}$, Xingeng $\mathrm{Li}^{1, \mathrm{~d}}$, Zengwu Yue ${ }^{1}$, \\ Min $\mathrm{Fu}^{1}$, Xuegang Wang ${ }^{1}$, Fengjie Yan ${ }^{1}$, Luo Qiang ${ }^{1}$ \\ ${ }^{1}$ Laboratory of Grid Metals Corrosion and Protection, State Grid Shandong Electric Power Research \\ Institute, Jinan 250002, China; \\ ${ }^{2}$ Water Company of Qingdao West Coast Municipal Group, Qingdao 266400, China. \\ akevin_guo1986@hotmail.com, b wxm612@163.com, ${ }^{\mathrm{c}}$ qdyzl126@126.com, ${ }^{\mathrm{d}}$ Ixgeng@126.com
}

Keywords: Aerial aluminum conductor; corrosion behavior; salt spray; shot blasting,corrosion resistance.

\begin{abstract}
Aerial aluminum conductor (ACSR) as the primary overhead lines products, has been running in the field for a long time. The inevitable corrosion will be affected by heavy pollution environment. Salt spray is acknowledged as the natural environment in most demanding of corrosion, which can make the wire obviously brittle and the strength greatly decreased. The resulting in ballooning and broken strands of the wire break will seriously affect the safe and reliable operation of power grid. Steel core aluminum stranded wires with shot blasting on their main body status are hard to shake in the current and future decades, and the shot blasting of ACSR is effective way to improve its corrosion resistance for great significance.
\end{abstract}

\section{Introduction}

ACSR conductor is made up of inner and outer aluminium wire and galvanized steel core wire twisted together in a kind of composite structure. After atmospheric corrosion, ACSR conductor mechanical properties and electrical properties are reduced, and may lead to line broken stocks, bolt, or even a power outage accidents. Himself at home and abroad such as aluminium and its alloy and zinc on corrosion behavior under different atmospheric corrosion medium to carry out the more basic research [1-3], but due to the complexity of ACSR conductor composition and structure, the composition of the corrosion behavior and corrosion products, structure more complicated [4].For the first time under laboratory conditions, such as through a cyclical wet/dry salt spray environment under the accelerated corrosion test to study the corrosion behavior of aluminum, steel and galvanized steel, based on the mass loss of the wire to evaluate degree of atmospheric corrosion of the wire, start the transmission wire corrosion behavior of laboratory research by Wang, etc [5]. Zhengyao [6] has been adopting NaHSO3 + NaCI to zinc ion in aqueous solution and aluminum alloy atmospheric corrosion process of research, the main research results and field exposure experiment results are identical with each other[7-9].

At present, in view of the steel core aluminum stranded wire anticorrosion measures mainly exist the following two ways: one is change the material of wire;Secondly, stranded wire attached other corrosion resistant performance is good or have physical isolation effect of materials. In order to improve the corrosion resistance of steel core aluminum stranded wire, usually between the steel core wire and aluminum twisted coated with organic anti-corrosion grease, in order to stop the rain and the corrosive gas corrosion of steel core, to prolong the life of steel reinforced, can match the life of aluminium wire. Depending on the paint coating position steel core aluminum stranded wire can be divided into three categories: coating anticorrosive coatings on steel reinforced, called light corrosion core aluminium conductor; Inside the steel core and coating anticorrosive coating on aluminium wire in each layer, called the anti-corrosion steel core aluminum stranded wire; On the outer aluminum wire is coated with anticorrosive coatings, called heavy-duty steel core aluminum stranded wire[10]. As early as in 1927 the United States for the first time the line coated on wire connector, some 
countries in Europe and Japan after the use of asphalt mixture, the mixture of lanolin, the mixture of grease, special metal soap grease mixture as the anti-corrosion material. Because of the anti-corrosion grease can increase the wire weight, long-term use can make the wire aging failure, so people began to adopt the way of the galvanized steel reinforced surface directly for corrosion protection. In order to improve the corrosion resistance of galvanized layer effect, adding in the process of galvanized tin. Because the galvanized layer between the conductor and is easy to form a galvanic cell constitute a galvanic corrosion, people create the contact between the wires of the bearing and the conductive part of the same aluminum metal package steel core aluminum stranded wire, steel wire life extension about 1 times[11]. In order to improve the overall performance of the wire, and then produce the rare earth aluminium stranded wire and steel core aluminum stranded wire, extend life of steel wire for more than 3 to 4 times. The wire has good anti-corrosion performance, applicable to the coastal lagoon, salty sand area and industrial area of high pressure, super high pressure and general electric line. In order to avoid the impact of corrosion on a wire, national science and technology workers seeking ideal aerial conducting online racking their brains [12].

\section{Experimental details}

\section{Materials.}

Experimental study on the object mainly steel core aluminum stranded wire. Due to the corrosion of steel core aluminum stranded wire involve the galvanized steel wire, in order to clear the research degree of changes in the aluminum wire in the aerial aluminum conductor, at the same time as the research object of the monofilament aluminium wire too. Sample treatment process include: untreated, preoxidation, shot peening, shot peening+preoxidation. Specimen preparation, regardless of the aerial aluminum conductor or aluminum monofilament, because to avoid the influence of the shot peening, sample requirements packaging on both ends. Packaging material requirements have a certain strength, resistance to $65{ }^{\circ} \mathrm{C}$, salt fog resistance, anti water imbibition, so packaging material selection for silicone and epoxy resin, salt spray test for long time using the epoxy resin sealing, electrochemical test using silica gel. Shot peening technology choice for 60 \# glass pill granule, preoxidation parameters of $250{ }^{\circ} \mathrm{C}$ for two hours.

\section{NSS Corrosion test.}

Considering the main coastal salt fog environment on the corrosion of aluminium conductor, choose neutral salt fog test method and copper acetic acid salt spray test, with reference to the standard "artificial atmosphere corrosion test, salt fog test" (GBT 10125-2012).Because the actual overhead stranded wire used for horizontal hanging, so select all samples selected for the level of suspension.

\section{Results and Discussion}

\section{Shot peening and pre oxidation.}

Four kinds of aluminum monofilament before and after the corrosion and the appearance of after cleaning as shown in figure 5, 6, 7, after the corrosion corrosion products color and shape difference is not big, but not processing of the surface of the aluminum monofilament appeared a deeper point corrosion pit, corrosion products rough; And shot peening+pre aluminum monofilament corrosion products relatively smooth, not very loose. On the corrosion of $500 \mathrm{~h}$ sample according to the national standard on the corrosion of metal and alloy corrosion sample removal of corrosion products (GBT 16545-1996) for cleaning, after cleaning showed untreated aluminum monofilament corrosion is most serious, deepest pit corrosion; Shot peening aluminum monofilament corrosion pit is a bit shallow, but a lot; Monofilament of alumina surface corrosion pit is very much also, more shallow than shot peening aluminum monofilament corrosion pit; Shot peening+pre aluminum monofilament corrosion pit number less than aluminum shot peening monofilament, pitting characteristics significantly, but after pitting transverse direction, the pitting corrosion pit generally shallow. 

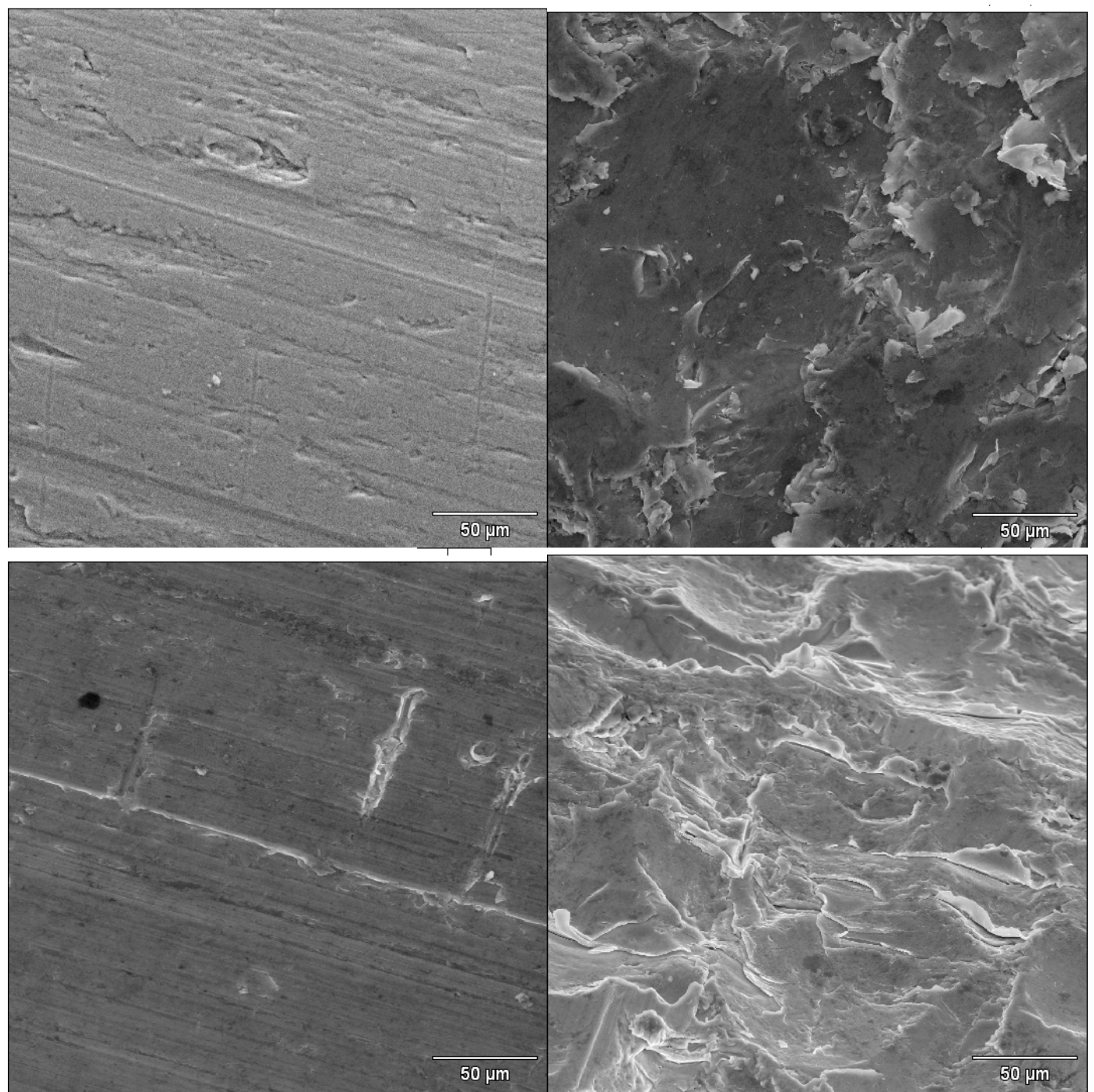

Fig.1. Four kinds of monofilament initial morphology, (a) untreated, (b) shot peening, (c) pre

\section{Corrosion behavior.} oxidation, (d) shot peening + pre oxidation.

1) Surface analysis by SEM

After $500 \mathrm{~h}$ of copper acetic acid salt spray after the accelerated corrosion test, four kinds of aluminum monofilament surface morphology difference is very big also, figure 10, 11 were magnified 500 times and 1000 times respectively of morphology. Untreated aluminum monofilament after corrosion, the surface corrosion products accumulation is serious, the product structure is loose, there is a clear wide and deep cracks, corrosion products can be bulky, jagged edges. After shot peening processing aluminum monofilament corrosion, the surface corrosion products is also very serious, relatively unprocessed aluminum monofilament, dense product a lot, but there are still many empty smile, zoom in to 1000 times still see some loose corrosion products, particles smaller than untreated. 


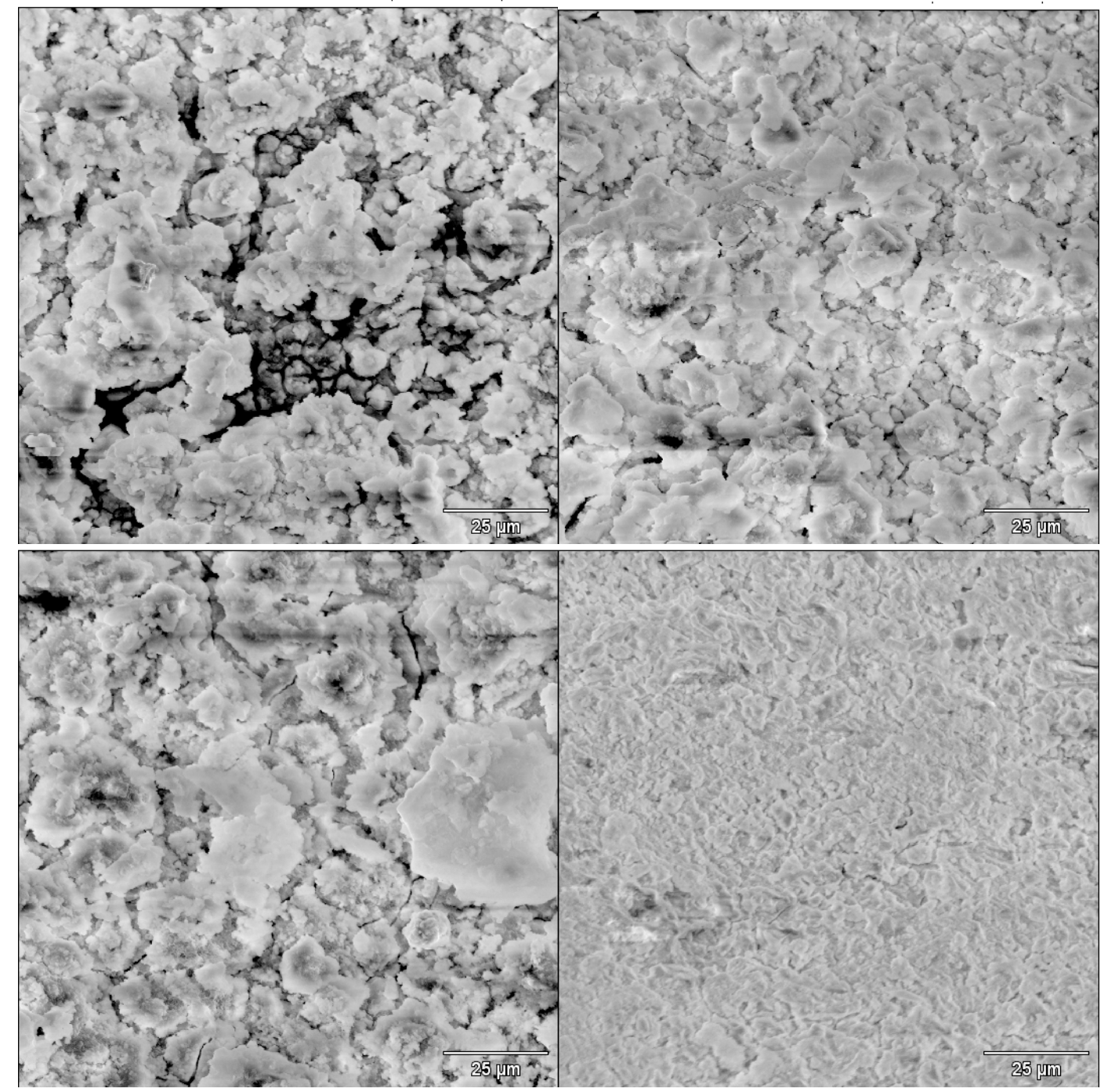

Fig.2. Four kinds of monofilament copper acetic acid salt spray corrosion morphology after $500 \mathrm{~h}$ : (a) untreated, (b) shot peening, (c) pre oxidation, (d) shot peening + pre oxidation.

After alumina monofilament corrosion, surface corrosion products accumulation is still very serious, the density of the product and its crack between untreated aluminum monofilament and shot peening monofilament, between product particles most uneven, but the surface of the product than the untreated aluminum monofilament slightly flat and level.

2) Dynamics analysis

According to the prophase preparatory found aerial aluminum conductor in the salt spray test period is longer, so the earliest started a neutral salt spray test, due to the limited subject early trials using aerial aluminum conductor, therefore subjects only chose the untreated and shot peening + preoxidation two sample.

As we known, the mass loss in salt spray corrosion test can been expressed as:

$$
v_{\text {loss }}=\frac{W_{O}-W_{1}}{S_{O} t}\left(g / m^{2} \cdot h\right)
$$

The variation in thickness can been express as:

$$
v_{\text {weight }}=\frac{W_{2}-W_{O}}{S_{O} t}\left(\mathrm{~g} / \mathrm{m}^{2} \bullet \mathrm{h}\right)
$$

We can substitute an corrosion change to Eq. (1) and combine with Eq. (2) for $D_{\text {thinkness }}$ is the variation in thickness where the changs occurs:

$$
D_{\text {thinkness }}=\frac{v_{\text {loss }} \times 8.76}{\rho}(\mathrm{mm} / \mathrm{a})
$$


Neutral salt spray test in accordance with the standard "artificial atmosphere corrosion test, salt fog test" (GBT 10125-2012).After nearly $2000 \mathrm{~h}$ of salt spray test, the two kinds of processing technology of aerial aluminum conductor corrosion dynamics curve as shown in Figure 2. The results show that the untreated aerial aluminum conductor in front of the corrosion of 500 h quality change is not obvious, changed obviously in $500 \mathrm{~h} \sim 740 \mathrm{~h}$ interval, weight loss, after quality is in a state change is not obvious; And shot peening + pre oxidation treatment of aerial aluminum conductor quality has been in a state of increasing. And found in untreated sample soaked in distilled water in the middle of aerial aluminum conductor surface appear white falls off a large number of small particles, and shot peening + pre oxidation treatment of aerial aluminum conductor loss, although there is also a small white particles quantity is obviously a lot less. Suggesting that untreated aerial aluminum conductor in neutral salt fog corrosion products and substrate is poorer, it is easy to fall off, and corrosion products of the growth process should be gradually grew up, the process of gradually become loose, in about $500 \mathrm{~h} \sim 740 \mathrm{~h}$ corrosion products become very loose a lot of peeling, later in the process of corrosion products growing.

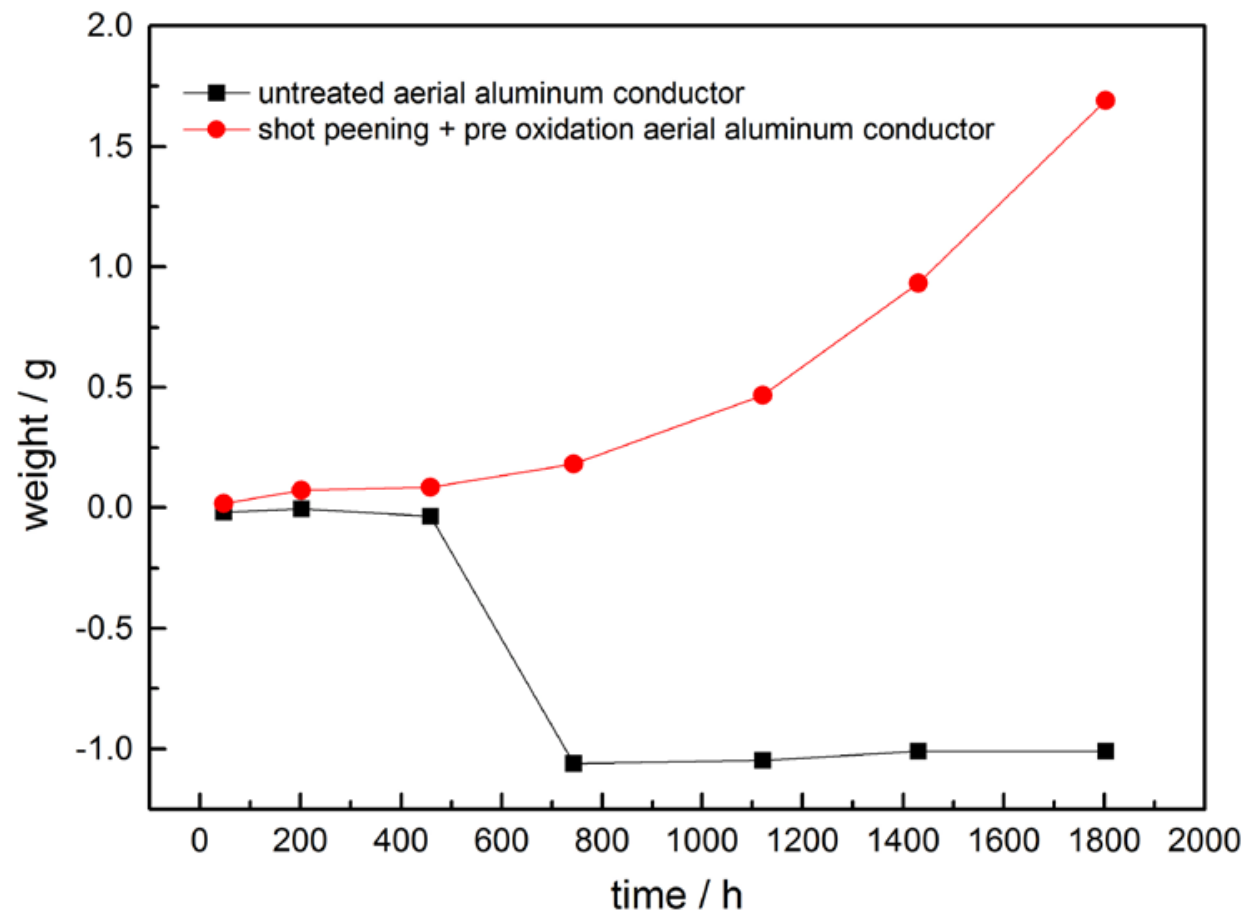

Fig.3. Salt spray dynamics analysis.

Shot peening + pre oxidation treatment of aerial aluminum conductor quality has been on the rise.It generated by the corrosion products and substrate with relatively strong, from the Angle of the corrosion process of blocking effect of corrosion products, shot peening + pre oxidation treatment of aerial aluminum conductor corrosion resistance will be improved.

\section{Conclusion}

Four kind of technology in the process of the steel core aluminum stranded wire weight have weightlessness, basically all appeared twice, in terms of relative aluminum monofilament has delayed the time of the weightlessness, including untreated steel core aluminum stranded wire delay time is the smallest, sharp and shot peening plus pre oxidation treatment of steel core aluminum stranded wire is one of the largest, weightlessness delay its second weightlessness delay in 450 hours, and weight loss is small. 


\section{References}

[1] FUENTE D D,OTERO.HUERTA E,MORCILLO M.Studies of long-term weathering of aluminum in the atmosphere[J].Corrosion Science,2007,49:3134-3148.

[2] VERA \& DELGADO D,ROSALES B M.Effect ofatmospheric pollutants on the corrosion of high power electrical conductors:Part 1.aluminum and AA6201 alloy[J].Corrosion Science,2006,48:2882-2900.

[3] LYON S B,THOMPSON G E,JOHNSON J B.Accelerated atmospheric corrosion testing using a cyclic wet / dry exposure test:aluminum,galvanized steel and steel[J].Corrosion,1987,43:719-726.

[4] WANG Zh'en·yao,MA Teng,HAN Wei,YU Guo-cai.Corrosion behavior on aluminum LYl2 in simulated atmospheric corrosion process[J].Transactions of Nonferrous Metals Society of China, 2007.17:326-334.

[5] SERNA L M, JOHNSON C M, WALL F D, et al. Effect of implanted Cl-and deposited oxides on pitting behavior of aluminum[J]. Journal of the Electrochemical Society, 2005,152(7):B244-B249.

[6] Liao C.M, OliveJ.M, GaoMet.al, In-situ monitoring of pitting corrosion in aluminum alloy2024[J].Corrosion,1998,54(6):451-459.

[7] Kalmykov V V, Razdobreev V G. Effect of the structure of carbonsteel on its corrosion in 3\% $\mathrm{NaCl}$ solution under alternating immersion[J]. Protection of Metals, 1999,35(6):598-599.

[8] Ralston K D, Birbilis N, Davies C H J. Revealing the relationship between grain size and corrosion rate of metals[J]. Scripata Materialia, 2010,63:1201-1204.

[9] Ralston K D, Fabijanic D, Birbilis N. Effect of grain size on corrosion of high purity aluminum[J]. Electrochimica Acta, 2011,56:1729-1736.

[10] Wang X Y,Li DJ.Mechanical and electrochemical behavior of nanocrystalline and surface of 304 stainless steel.Electrochim Aeta,2002,47:3939.

[11] W. BENSALAH, M. FEKI .Chemical dissolution resistance of anodic oxide layers formed on aluminum[J]. Trans. Nonferrous Met. Soc.

[12] Liu Xiao-dong, Frankel G S, Zoofan B, et al. Effect of applied tensile stress on intergranular corrosion of AA2024-T3[J]. Corrosion Science. 2004, 46:405 425. 